\title{
Um deserto de palavras, uma biblioteca de areia: a coleção em Benjamin e Calvino
}

\author{
A desert of words, a library of sand: \\ collection in Benjamin and Calvino
}

\author{
Bruna Fontes Ferraz \\ Universidade Federal de Minas Gerais, Belo Horizonte, Brasil \\ brunafferraz@gmail.com
}

Resumo: Neste texto, pretende-se refletir sobre a relação enigmática estabelecida entre um colecionador e as peças de sua coleção, como um encontro fortuito e marcado pelo desejo. Assim, por ser sempre uma escolha casual e pessoal, qualquer quinquilharia pode interessar ao colecionador, que vê nesta um resumo do mundo. Entre a dispersão e o vazio, a desordem e a ordem, funda-se uma coleção como promessa de uma perenidade que sempre se dissipa em seu propósito. Por isso dois emblemas guiarão este estudo: o da biblioteca e o do deserto, símbolos ao mesmo tempo do infinito e da incompletude. Como essas imagens nos remetem ao solitário espaço da linguagem, analisaremos dois paradigmáticos escritores, Walter Benjamin e Italo Calvino, por terem sido em vida colecionadores de palavras.

Palavras-chave: coleção; Walter Benjamin; Italo Calvino.

\begin{abstract}
This paper intends to reflect on the enigmatic relationship, established between a collector and the items of his collection, as a chance encounter marked by desire. Thus, as it is always a casual and personal choice, any stuff may be of interest to collectors, who see in that a summary of the world. Among dispersion and emptiness, disorder and order, a collection is founded as a promise to the perennial, which always dissipates in its purpose. That is why two emblems will guide this study: the library and the desert that symbolizes simultaneously the infinite and the incompleteness. As these images insert us in the solitary space of language, we will analyze two paradigmatic writers, Walter Benjamin and Italo Calvino, who were themselves collectors of words in life.
\end{abstract}

Keywords: collection; Walter Benjamin; Italo Calvino.

As citações são no meu trabalho como salteadores à beira da estrada, que irrompem armados e retiram ao ocioso caminhante a sua convicção.

Walter Benjamin. 
Os próprios dias, minuto por minuto, pensamento por pensamento, reduzidos a coleção: a vida triturada numa poalha de grãos - a areia, ainda.

Ítalo Calvino.

Para um colecionador autêntico tudo é passível de ser colecionado, pois lhe interessam justamente os vestígios, os resíduos, os fragmentos encontrados em cada nova busca, em cada lugar (re)visitado. A coleção desses resíduos guarda memórias, por isso as melhores peças são adquiridas em viagem, quando as caminhadas e flanagens sem rumo definido fazem surgir, como que por acaso, num golpe de sorte, aquele objeto singular, cuja razão de ser só se verifica ao lado das outras peças na coleção.

Flanam, pois, por este texto dois paradigmáticos colecionadores: Walter Benjamin e Italo Calvino. Embora arbitrário, o encontro desses autores se justifica por terem sido em vida colecionadores de palavras: se Benjamin tentou encerrar a totalidade em um único livro, na incompleta e fragmentária obra das Passagens, Calvino, por sua vez, perseguiu a multiplicidade colecionando livros de sua própria autoria. Um objeto ínfimo foi, assim, colecionado por esses dois personagens: as letras do alfabeto. Como uma poeira, como um grão de areia, as letras se dispersam, possibilitando formar, além de produções simbólicas, experiências: a vida numa poalha de grãos, letras e palavras.

Desses colecionadores de palavras, dois textos ganham destaque especial: "Desempacotando a minha biblioteca", de Benjamin, e "Coleção de areia", de Calvino, por nos possibilitarem dois emblemas: a biblioteca e o deserto. Enquanto o filósofo alemão, imerso no caos de caixas repletas de livros a serem dispostos nas prateleiras de sua biblioteca, encontrou refúgio no solitário deserto da linguagem; o escritor italiano, ao analisar a coleção de areia exposta num museu, em sua ânsia classificatória, organizou e catalogou frascos de areia em uma biblioteca.

A biblioteca e o deserto como símbolos do infinito e da dispersão nos permitirão, portanto, percorrer a imagem que Benjamin e Calvino faziam da coleção, como um acúmulo de memórias, palavras e pequenas quinquilharias.

\section{Um deserto de palavras}

Imerso na desordem e no caos, numa noite lúgubre, entre um ar polvoroso e o chão repleto de papéis rasgados, jazia Walter Benjamin a desempacotar a sua biblioteca. $\mathrm{O}$ ambiente obscuro e tenso dessa cena revela, talvez, o próprio estado de espírito desse declarado colecionador de livros, que se dissipava do mundo real para desaparecer dentro de sua coleção (BENJAMIN, 2013, p. 97). A desordem dos livros ainda dentro das caixas faz surgir o imperativo da ordem, quando os livros, respeitando a um esquema de catalogação e classificação, estarão nas prateleiras, envolvidos pelo "tédio silencioso da ordem" (BENJAMIN, 2013, p. 89). 
"Assim, a existência do colecionador assenta numa tensão dialética entre os polos da desordem e da ordem" (BENJAMIN, 2013, p. 90). Se as coisas vão de encontro ao colecionador, chocam-se contra ele, como estilhaços caóticos e desordenados, cabe a esse frenético ajuntador dispô-las em um mundo particular: "o grande colecionador é tocado pela confusão, pela dispersão em que se encontram as coisas no mundo" (BENJAMIN, 2007, p. 245). Mas, contra essa dispersão, da qual ele próprio é parte constituinte, impera uma nova ordem, imposta pelo colecionador ao libertar esses objetos do mundo da servidão de serem úteis, reinvestindo-os de um outro valor, um valor afetivo.

O colecionador liberta as coisas, assim como estas também o libertam. Esse grande acumulador parece desafinado com o mundo em que vive, não entende a sua lógica, lançando sobre o real um olhar próprio, como se visse algo que os outros (os não colecionadores) jamais possuiriam a capacidade de ver: "o colecionador consegue lançar um olhar incomparável sobre o objeto, um olhar que vê mais e enxerga diferentes coisas" (BENJAMIN, 2007, p. 241). Por isso, Benjamin é acometido pela necessidade de ordenação, deve organizar seus livros, dispô-los em sua nova biblioteca, por meio de uma ordem. Ordem, porém, "segundo um arranjo surpreendente, incompreensível para uma mente profana" (BENJAMIN, 2007, p. 241). Assim, mesmo que a escolha pela coleção seja de ordem tátil e sensível, como indicou Benjamin, criá-la requer a sua ordenação, mesmo que tal critério de organização seja compreensível somente ao colecionador, pois cabe a ele retirar aquele objeto de sua dispersão e funcionalidade e investi-lo de uma carga cultural.

Seria, ainda, incompreensível a uma mente profana a escolha pelo objeto de desejo que ocupará um lugar especial na coleção. Pois, qualquer objeto poderia ser investido pelo interesse e pela fome do colecionador. "O quodlibet possui algo do engenho do colecionador" (BENJAMIN, 2007, p. 244). Não se trata, porém, de uma indiferença, conforme pontuou Giorgio Agamben em A comunidade que vem:

\footnotetext{
A tradução corrente, no sentido de "qualquer um, indiferentemente", é certamente correta, mas, quanto à forma, diz exatamente o contrário do latim: quodlibet ens não é "o ser, qualquer ser", mas "o ser que, seja como for, não é indiferente"; ele contém, desde logo, algo que remete para vontade (libet), o ser qual-quer estabelece uma relação original com o desejo (AGAMBEN, 1993, p. 11).
}

Há, portanto, uma relação de desejo que se estabelece entre o colecionador e o objeto eleito, este é desejado independentemente de qualquer atributo ou valor comercial. Nesse sentido, o colecionador não reflete sobre o motivo de sua coleção, não a elege racionalmente, pois que ela surge como um ímpeto do acaso, do destino.

A ideia de casualidade a unir o colecionador à peça da coleção é reforçada por Benjamin ao relatar a busca pelos livros que integrariam a sua coleção. A imprevisibilidade desse encontro torna-se ainda mais determinante quando o filósofo, como um transeunte, vagueia por cidades, que se abriam a ele, revelando-lhe singulares peças para compor sua coleção:

As minhas compras mais memoráveis fi-las em viagem, como transeunte. A propriedade e o ter subordinam-se à tática. Os colecionadores são pessoas com 
instinto tático; a sua experiência diz-lhes que, ao tomarem de assalto uma cidade, o menor alfarrabista pode ser um forte, a papelaria mais fora de mão, uma posiçãochave. Quantas cidades não se abriram para mim nas caminhadas que fiz em busca de livros! (BENJAMIN, 2013, p. 92-93).

Reorganizar, portanto, a coleção, como faz Benjamin, é ser acometido por um turbilhão de lembranças que se chocam contra ele ao tocar novamente aquele objeto. Destituído de sua função, ${ }^{1}$ por estar em outro contexto, ou mesmo destituído de qualquer significado, para uma mente profana, o objeto de coleção guarda memórias inconfessáveis, compartilhadas somente entre ele e o colecionador. Por isso, os livros de Benjamin o lembram das cidades onde esteve, quando os adquiriu, reminiscências únicas, pessoais, pois a coleção só porta um sentido para o seu colecionador:

[...] estou diante da última caixa, meio vazia, e já passa muito da meia-noite. Afluem outros pensamentos, diferentes daqueles de que falei. Pensamentos, não: imagens, memórias. Recordações das cidades em que encontrei tanta coisa: Riga, Nápoles, Munique, Danzig, Moscou, Florença, Basileia, Paris; recordações das suntuosas salas de Rosenthal em Munique, da "Stockturm" (Torre dos Brasões) de Danzig, onde vivia o falecido Hans Rhaue, do porão cheio de livros e de mofo de SüBengut, em Berlim Norte; recordações dos quartos onde tinha esses livros, do meu alojamento de estudante em Munique, do meu quarto em Berna, da solidão de Iseltwald no Lago de Brienz, e finalmente o meu quarto de criança, de onde provêm apenas quatro ou cinco dos muitos milhares de livros que começam a avolumar-se à minha volta (BENJAMIN, 2013, p. 96-97).

A relação com o objeto de desejo torna-se enigmática quando o colecionador decide petrificá-lo em um "círculo mágico" (BENJAMIN, 2013, p. 90), ou seja, na coleção: a peça fica petrificada como uma mônada, como um pequeno resumo do universo. Por isso um simples objeto, como uma concha reunida a outras em uma exposição, conforme afirma Benjamin no trecho $\mathrm{H}(1 \mathrm{a}, 3)$ das Passagens (BENJAMIN, 2007, p. 239), pode adquirir inúmeros outros sentidos, pode remeter a todos os mares da Terra, mas só para aquele que o coletou. A peça da coleção adquire, assim, um valor mágico, pois produz efeitos fascinantes e encantatórios no seu colecionador.

No caso de Benjamin, a mágica acontece na viagem empreendida ao tocar o objeto colecionável, o livro, já que, independente do que este relata, o objeto livro o porta aos lugares por onde esteve durante a sua aquisição. A biblioteca de Benjamin o recorda de sua solidão em meio aos livros bolorentos e empoeirados, o recorda de seus quartos de cada uma das cidades descritas por ele na citação evidenciada, o recorda de seu deserto pessoal.

\footnotetext{
${ }^{1}$ Embora o colecionador de livros seja o único que não desvinculou as peças da coleção de seu contexto funcional, pois, mesmo em uma coleção, os livros continuam cumprindo o propósito da leitura, a partir do momento no qual adquirem um valor também afetivo, como peça única e singular para aquele que o reúne, eles passam a ter uma relação enigmática com o colecionador, conforme considerou Benjamin em "Desempacotando a minha biblioteca", como se assumissem um pacto, como se ambos guardassem os segredos mais obscuros do outro. Por isso, os objetos de coleção, assim como os livros para Benjamin, portam memórias só identificadas e reconhecidas para o próprio colecionador.
} 
No claustro de um quarto, entre caixas abertas e com um livro nas mãos: este é o deserto penetrado por Benjamin, um deserto de palavras.

\section{Uma biblioteca de areia}

Enquanto a imagem do deserto nos serviu como alegoria para pensarmos a relação entre Benjamin e a coleção, o qual, antes mesmo de colecionar livros, colecionava palavras e saberes, Calvino, por sua vez, depara-se com a Waste Land, o próprio deserto desmembrado, fragmentado e ensacado em pequenos recipientes.

Essa aventura do colecionador será, pois, experimentada por Calvino enquanto visitava uma exposição de coleções estranhas em Paris, na qual, ao observar cada objeto de uma coleção, buscava desvendar não só a história daquele colecionador, como também efetuar uma busca de si próprio mediante a observação daqueles objetos insólitos. Nesse sentido, o espírito de colecionador foi despertado em Calvino para "coisas impalpáveis, como as imagens de velhos filmes, coleção de lembranças, de sombras brancas e pretas" (CALVINO, 2006, p. 189).

Entre as várias coleções vistas na exposição - "coleções de chocalhos de vacas, de jogos de tômbola, de tampas de garrafa, de apitos de terracota, de tíquetes ferroviários, de piões, de invólucros de rolos de papel higiênico, de distintivos colaboracionistas da ocupação, de rãs embalsamadas" (CALVINO, 2010, p. 11) -, aquela que mais lhe chamou a atenção foi a vitrine da coleção de areia, a seu ver a mais misteriosa justamente por revelar por meio da areia, símbolo ao mesmo tempo de infinitude e dispersão, os vários lugares visitados pelo colecionador. Assim, Calvino inicia o seu relato indicando que:

\footnotetext{
Há uma pessoa que faz coleção de areia. Viaja pelo mundo e, quando chega a uma praia de mar, à orla de um rio ou de um lago, a um deserto, a uma charneca, recolhe um punhado de areia e o carrega consigo. Na volta, esperam-na alinhadas em longas prateleiras centenas de frasquinhos de vidro nos quais a fina areia cinzenta do Balaton, a areia alvíssima do golfo do Sião, a vermelha que o curso do Gâmbia deposita pelo Senegal abaixo desdobram sua limitada gama de cores esfumadas, revelam uma uniformidade de superfície lunar, mesmo passando por diferenças de granulosidade e consistência, do cascalhoso preto e branco do Cáspio, que parece ainda encharcado de água salina, aos minúsculos pedriscos de Maratea, igualmente pretos e brancos, à sutil farinha branca pontilhada de caracóis lilases de Turthe Bay, perto de Malindi, no Quênia (CALVINO, 2010, p. 11).
}

Nesse fragmento, o escritor italiano já nos aponta aspectos concernentes à coleção, ou seja, a sua impossibilidade de completude dada pela atitude excessiva de se apanhar "um punhado de areia" de um dado lugar e encher um frasquinho. Ressalta-se, ainda, que a ideia de preencher prateleiras e mais prateleiras com frasquinhos de areia do mundo inteiro, classificando-os e ordenando-os como livros em uma biblioteca, se faz um tanto quanto absurda, já que, se pensarmos que a areia, com um simples soprar do vento, se dispersa, jamais aquele "punhado de areia" poderia representar exatamente um dado lugar, assim como 
sua referência se perderia se a sua etiqueta fosse removida. Entretanto, se a areia precisaria desses subsídios de organização para explicitar a sua origem a uma mente profana, ao colecionador, cada grão, aprisionado no vidro das ampolas, remeteria a inúmeras memórias, não só de seu referente, mas ainda de cada gesto, sabores e pessoas encontrados no lugar onde coletou aquela ampola de areia.

A coleção traz, portanto, memórias únicas ao colecionador. Benjamin afirma que o processo de colecionar "é apenas um dique contra a maré das recordações que avança na direção de qualquer colecionador que se ocupa do que adquiriu" (BENJAMIN, 2013, p. 90). É, pois, sob essa perspectiva que Calvino se questionará se a coleção nos revela: "uma descrição do mundo? Um diário secreto do colecionador? Ou um oráculo sobre mim, que estou a escrutar nestas ampulhetas imóveis minha hora de chegada?" (CALVINO, 2010, p. 12). Se, como diz o escritor italiano, a coleção nos revela tudo isso em alguma medida, podemos perceber que a coleção de areia deslinda "todos os cenários da vida do colecionador [...] evocados e ao mesmo tempo cancelados pelo gesto já compulsivo de inclinar-se para recolher um pouco de areia e encher um saquinho" (CALVINO, 2010, p. 12).

O gesto de recolher o objeto colecionável guarda, portanto, uma memória muito particular da vida do colecionador. É nesse sentido que Calvino perceberá que toda coleção é também um diário:

É que, como toda coleção, esta também é um diário: diário de viagens, claro, mas também diário de sentimentos, de estados de ânimo, de humores; ainda que não possamos estar seguros de que realmente exista uma correspondência entre a fria areia cor de terra de Leningrado ou a finíssima areia de Copacabana e os sentimentos que elas evocam quando as vemos aqui, engarrafadas e etiquetadas. Ou talvez apenas diário daquela obscura agitação que leva tanto a reunir uma coleção quanto a manter um diário, isto é, a necessidade de transformar o escorrer da própria existência numa série de objetos salvos da dispersão, ou numa série de linhas escritas, cristalizadas fora do fluxo contínuo dos pensamentos (CALVINO, 2010, p. 13).

Mas, se a coleção pode nos revelar a vida do colecionador, com seus sentimentos e humores, ela, ao mesmo tempo, nos esconde o impulso que o levou a criá-la, sobretudo, se nos deparamos com objetos estranhos e insólitos, como é o caso da areia. Para Mario Perniola, o critério de escolha das coleções artísticas é muito enigmático, tem a ver com o desejo, com o quodlibet no sentido defendido por Agamben, sendo que esses objetos foram "investidos de um significado cultural simplesmente porque foram pré-selecionados e conservados pelo artista" (PERNIOLA, 2009, p. 132).

Benjamin afirma que "colecionadores são pessoas com instinto tátil" (BENJAMIN, 2007, p. 241) ao nos mostrar que, "na modernidade, colecionar objetos é, antes de mais nada, valorizar suas qualidades sensíveis" (OTTE, 2011, p. 14). O colecionador é, pois, tocado pela dispersão em que se encontram as coisas no mundo, é sensível para o que é considerado resto, entulho, objeto de pouco valor e, justamente por isso, os recolhe e os coleciona.

É com os objetos menores que a vida será equiparada, pois, como nos diz Beatriz Sarlo a respeito das Passagens, de Benjamin, "o olhar que ilumina o banal produz, ao 
incorporá-lo à coleção ou ao relato, uma verdade" (SARLO, 2000, p. 38, tradução nossa), ${ }^{2}$ já que, para Benjamin, o verdadeiramente significativo estaria no pequeno e no trivial. Essa ideia coincide com aquela em que acredita Perniola ao considerar que na modernidade há "uma febre que multiplica as coleções ao infinito, de acordo com uma lógica que não é aquela do trânsito e do enigma, mas, ao contrário, a da identidade e a do banal" (PERNIOLA, 2009, p. 135).

É justamente esse caráter aparentemente banal dos objetos de coleção que nos revela a identidade do colecionador, como indica uma das colecionadoras da exposição visitada por Calvino, ao afirmar que, para montar a sua coleção, necessitava folhear, recolher, ordenar, classificar, peneirar, reduzir para apropriar-se da vida e incorporá-la à sua coleção (CALVINO, 2010, p. 14). Para o colecionador, o mundo está presente em cada um de seus objetos, que, combinados a outros, leva a uma determinada constelação. A coleção seria, assim, uma constelação.

Nesse sentido, o objeto, ao ser colecionado e posto ao lado de outros em uma constelação, perde a sua significação funcional $^{3}$ e será ressignificado, reinvestido por um novo valor que lhe será concedido pelo olhar e pelo desejo do colecionador, como afirmado por Benjamin: "é decisivo na arte de colecionar que o objeto seja desligado de todas as suas funções primitivas, a fim de travar a relação mais íntima que se pode imaginar com aquilo que lhe é semelhante" (BENJAMIN, 2007, p. 239). Assim, o colecionador renova o mundo velho ao investi-lo de uma carga mágica, pois "o mais profundo encantamento do colecionador consiste em inscrever a coisa particular em um círculo mágico no qual ela se imobiliza, enquanto a percorre um último estremecimento (o estremecimento de ser adquirida)" (BENJAMIN, 2007, p. 239).

Embora com a coleção todos os objetos sejam transformados num tesouro, para Perniola esse objeto só se configurará como um bem cultural por estar imerso no espaço da coleção, uma vez que, fora desse espaço, o objeto perderia o seu valor. Nas suas palavras:

A coleção introduz a noção de espaço como campo; o campo aberto pela coleção é o conjunto das condições que tornam possível a transformação de um objeto em bem cultural. O que determina o bem cultural como tal é o seu estar contido dentro de um campo: fora de tal espaço o objeto apresenta um interesse muito menor (PERNIOLA, 2009, p. 132).

O trabalho do colecionador consiste, portanto, em retirar os objetos da dispersão, dando-lhes uma ordem ao subtrair-lhes seu valor de uso, trabalho esse contínuo e inalcançável, como nos esclarece Beatriz Sarlo:

O colecionador [...] despoja a mercadoria de seu valor de uso, a subtrai de sua função prática, suspende sua circulação, para incorporá-la a um espaço ordenado e artificial, impulsionado por um impossível e nunca resignado desejo de totalidade.

\footnotetext{
${ }^{2}$ No original: "la mirada que ilumina lo banal produciendo, al incorporarlo a la colección o al relato, una verdad".

${ }^{3}$ É necessário ressaltar que o objeto arrancado de seu contexto sempre carrega algo dele consigo, pois o objeto possui um caráter metonímico que evoca, pela sua mera presença, o contexto (ausente).
} 
Um trabalho utópico, já que por definição e por sua própria lógica não pode existir coleção completa; a paixão do colecionador se alimenta precisamente do desejo de completude e de saber que ela é, no melhor dos casos, provisória (SARLO, 2000, p. 36 , tradução nossa). ${ }^{4}$

No entanto, se o objeto adquire um novo significado ao pertencer a uma dada coleção, podemos nos perguntar se ele, de fato, manterá relações com o seu lugar de origem, tal como se questiona Calvino ao perceber que a areia colecionada num frasquinho não é mais capaz de conservar o brilho da praia e o seu calor úmido:

E então está de volta de uma viagem, acrescenta novos frasquinhos aos outros em fila e de repente se dá conta de que, sem o índigo do mar, o brilho daquela praia de conchas moídas se perdeu, que do calor úmido dos uádis nada restou na areia encapsulada, que, distante do México, a terra misturada à lava do vulcão Paricutín é um pó negro que parece varrido da garganta de uma lareira. Tenta reconduzir à memória as sensações daquela praia, aquele cheiro de floresta, aquela ardência, mas é como sacudir aquele pouco de areia no fundo da garrafa etiquetada (CALVINO, 2010, p. 15).

É como se, de tanto querer lembrar os lugares visitados, a colecionadora de areia descrita por Calvino fracassasse em seu projeto, mesmo porque os frascos remeteriam mais a amostras científicas - de um geólogo, por exemplo - do que a um "souvenir" afetivo e aurático. Pensando sob essa perspectiva, a coleção de areia se tornaria um "cemitério de paisagens reduzidas a deserto, de desertos sobre os quais não sopra mais o vento" (CALVINO, 2010, p. 15). Não sopra mais o vento caótico do mundo, pois as areias foram organizadas e classificadas como livros em uma biblioteca. $\mathrm{O}$ espaço da coleção, assim como o espaço da biblioteca permitem esse ordenamento, esse isolamento confortável que se tem do mundo.

\section{Colecionar e ler o mundo}

Durante todo o ensaio, percebemos que a coleção foi contundentemente comparada à escrita, tanto em sua interface com a ideia de diário, por revelar algo de seu colecionador, quanto pela aproximação entre as imagens de rastros filiformes deixados na areia e a sucessão de palavras enfileiradas em uma página. Podemos depreender disso que colecionar e ler são gestos derivados um do outro, não à toa a raiz etimológica de coleção (collectio) deriva de legere, que, originariamente, remetia às ideias de colher, escolher, recolher. Três verbos que dizem tanto da prática exercida por um leitor, quanto do gesto físico do próprio colecionador: ambos colhem palavras e objetos, tirando-os da dispersão.

\footnotetext{
${ }^{4}$ No original: "El coleccionista, [...], despoja a la mercancía de su valor de uso, la sustrae de su función práctica, suspende su circulación, para incorporarla a un espacio ordenado y artificioso, impulsado por un imposible y nunca resignado deseo de totalidad. Un trabajo utópico, ya que por definición y por su propia lógica no puede existir colección completa; la pasión del coleccionista se alimenta precisamente del deseo de completitud y del saber que ella es, en el mejor de los casos, provisoria".
} 
A linguagem foi, portanto, o primeiro objeto de coleção que acometeu Benjamin e Calvino, pois que foram surpreendidos por palavras que, como salteadores à beira da estrada, para recuperarmos a imagem de Benjamin em epígrafe neste estudo, retiraram dos nossos colecionadores o poder de escolha, imergindo-os num universo linguístico. Antes, porém, de colecionadores, eles foram leitores do mundo: "colecionar é um fenômeno primevo do estudo: o estudante coleciona saber" (BENJAMIN, 2007, p. 245). Por isso, ao se deparar com a biblioteca de ampolas de areias da melancólica colecionadora, Calvino passa a refletir sobre o seu próprio deserto de palavras escritas em sua vida:

\begin{abstract}
Decifrando o diário da melancólica (ou feliz) colecionadora de areia, cheguei a interrogar-me sobre o que está escrito naquela areia de palavras escritas que enfileirei durante minha vida, aquela areia que agora me parece tão distante das praias e dos desertos da vida. Talvez fixando a areia como areia, as palavras como palavras, possamos chegar perto de entender como e em que medida o mundo triturado e erodido ainda possa encontrar nelas fundamento e modelo (CALVINO, 2010, p. 15-16).
\end{abstract}

Tanto Benjamin quanto Calvino recolheram, excessiva e compulsivamente, areias de palavras, preenchendo muitas páginas em branco. Esse gesto de colecionar pressupunha inovar tanto a relação com a escrita quanto a relação entre escritura e mundo. Assim, poderíamos pensar que a obra desses colecionadores se apresenta como coleções de pensamentos e saberes, impedindo que o conhecimento caia na dispersão e permitindo que ele se preserve na memória. É, pois, com tal propósito que percebemos a presença do mundo triturado nas coleções e na escrita, pois "os próprios dias, minuto por minuto, pensamento por pensamento, [estão] reduzidos a coleção: a vida triturada numa poalha de grãos - a areia, ainda" (CALVINO, 2010, p. 14). Colecionar é, portanto, perceber, em contínuos reavivamentos e reagrupamentos, a vida fragmentada em cada objeto que compõe a coleçãoconstelação.

\title{
Agradecimentos
}

Agradeço à Simone Garcia de Oliveira, pela tradução cuidadosa do resumo deste artigo para a língua inglesa.

\section{Referências}

AGAMBEN, Giorgio. A comunidade que vem. Tradução de António Guerreiro. Lisboa: Editorial Presença, 1993.

BENJAMIN, Walter. O colecionador. In: BENJAMIN, Walter. Passagens. Tradução de Irene Aron e Cleonice Paes Barreto Mourão. Belo Horizonte: Ed. UFMG; São Paulo: Imprensa Oficial do Estado de São Paulo, 2007. p. 237-246. 
BENJAMIN, Walter. Desempacotando a minha biblioteca. Uma palestra sobre o colecionador. In: BENJAMIN, Walter. Imagens do pensamento. Sobre o haxixe e outras drogas. Tradução de João Barrento. Belo Horizonte: Autêntica, 2013. p. 89-97.

CALVINO, Italo. Eremita em Paris. In: CALVINO, Italo. Eremita em Paris: páginas autobiográficas. Tradução de Roberta Barni. São Paulo: Companhia das Letras, 2006. p. 182190.

CALVINO, Italo. Coleção de areia. In: CALVINO, Italo. Coleção de areia. Tradução de Maurício Santana Dias. São Paulo: Companhia das Letras, 2010. p. 11-16.

OTTE, Georg. A natureza enquanto espaço da história e da literatura em Walter Benjamin. Projeto de pesquisa. 2011. [Não publicado].

PERNIOLA, Mario. O efeito barroco: o enigma da coleção. In: PERNIOLA, Mario. Enigmas: egípcio, barroco e neobarroco na sociedade e na arte. Tradução de Carolina Pizzolo Torquato. Chapecó: Argos, 2009.

SARLO, Beatriz. Siete ensayos sobre Walter Benjamin. Buenos Aires: Fondo de Cultura Económica, 2000. 